\title{
A IMPORTÂNCIA DA PRÁTICA DA SUSTENTABILIDADE E DE SEUS INDICADORES PARA IMPLEMENTAÇÃO E CONSOLIDAÇÃO DE VANTAGEM COMPETITIVA NAS ORGANIZAÇÕES EMPRESARIAIS.
}

Geraldo Jose Ferraresi de Araujo'

Cesar Machado Carvalho

Vanessa de Castro ${ }^{3}$

RESUMO: Com o aumento da degradação ambiental em escala mundial, desde o inicio da revolução industrial - na segunda metade do século XVIII na Inglaterra, a ampliação da pobreza, sobretudo nos países subdesenvolvidos, fez-se necessário que estados, governos, empresas, organizações não governamentais e sociedade civil reformulassem o presente modelo de desenvolvimento - o capitalismo - para que este pudesse contemplar a preservação ambiental, a promoção social e o desenvolvimento econômico. Isto posto, as organizações empresariais têm um papel de destaque nessa transformação. Para elaboração deste artigo, a metodologia utilizada foi a pesquisa qualitativa, de levantamento bibliográfico pela internet no período de 01/06/2013 até 30/06/2013 com enfoque em sustentabilidade, indicadores e vantagem competitiva, com o

\footnotetext{
1 Bacharel em Administração pela Faculdade de Economia, Administração e Contabilidade de Ribeirão Preto da Universidade de São Paulo (Avenida dos Bandeirantes 3900, CEP14040-900 - Ribeirão Preto/SP, Brasil). E mail: geraldoferraresi@gmail.com. Fone: 55163602 - 3916. Fax: 5516 3633-4411.

2 Mestre em Ciências Políticas pela Universidade Federal de São Carlos, Campus São Carlos (Rodovia Washington Luís, Km 235, CEP: 13565-905 - São Carlos/SP, Brasil) Email:cesarmc27@yahoo.com.br. Fone: (16) 3351-8369

3 Bacharel em Ciências Econômicas pela Universidade Estadual Paulista - Faculdade de Ciências e Letras - Júlio de Mesquita Filho - UNESP (Rodovia Araraquara-Jaú, Km 01, CEP 14800-901. Araraquara/SP, Brasil). Email: vanessaecounesp@gmail.com. Fone: 551636267924
} 
objetivo de responder à seguinte pergunta: como a aplicação dos princípios sustentáveis nas organizações empresariais, através dos indicadores de sustentabilidade, podem edificar e consolidar vantagem competitiva para as mesmas? Com a ampliação da concorrência em escala internacional, devido ao processo de globalização, as empresas que pretendem edificar e consolidar vantagem competitiva - que representa em linhas gerais agregar valor a todos os seus stakeholders (acionistas, colaboradores, fornecedores, sociedade, comunidade e sobretudo clientes) devem aplicar os princípios sustentáveis através dos indicadores de sustentabilidade para melhor construir e consolidar sua vantagem competitiva. Portanto, empresas que se adéquam aos desafios da economia internacional, através da preservação do meio ambiente e da promoção social, têm maiores condições de liderar seus respectivos mercados, como fundamentação pode-se a firmar que o Índice de Sustentabilidade Empresarial negociado na BMFBOVESPA - que em 2010 teve valorização de 5,84\%, maior do que o Índice Ibovespa, de 1,04\%.

Palavras Chave: Sustentabilidade. Empresas. Vantagem Competitiva.

\section{INTRODUÇÃO}

No inicio do século XXI, a competição entre empresas por novos mercados, mão de obra qualificada, informações e integração das cadeias produtivas para racionalização dos custos e otimização dos resultados se realiza em escala global.

Paralelo a esse processo de competitividade empresarial, a necessidade de mudanças no atual modelo de desenvolvimento ante o agravamento das questões ambientais, econômicas e sociais em escala mundial, aliados à pressão por parte de grandes mercados consumidores como: governos, empresas de grande e médio porte e consumidores finais por respeito ao meio ambiente e promoção da dignidade humana, prática de princípios sustentáveis, promoção do desenvolvimento econômico e social, paralela à preservação do meio ambiente, se faz cada vez mais necessária para 
empresas que desejam se manter competitivas em seus respectivos mercados no inicio desse século.

Sendo assim, o objetivo deste artigo é dissertar sobre a importância da aplicação dos princípios sustentáveis no exercício da gestão empresarial e como esta pode ser um diferencial competitivo.

Logo, a pergunta a ser respondida no presente artigo é: como a aplicação dos princípios sustentáveis nas organizações empresariais através dos indicadores de sustentabilidade podem edificar e consolidar vantagem competitiva para as mesmas?

Para responder a essa pergunta a metodologia utilizada foi a pesquisa qualitativa, de levantamento bibliográfico. Nesse sentido, a pesquisa bibliográfica é um trabalho de pesquisa de toda bibliografia já publicada em forma de livros, revistas, publicações avulsas e artigos que já debateram o tema investigado pelo pesquisador em seu trabalho cientifico. Trata-se, portanto de uma seleção de bibliografias que poderão ser utilizadas como referências na construção do artigo.

Ante o exposto acima, as referências bibliográficas foram levantadas pela internet no período de 01/06/2013 até 30/06/2013, com enfoque em sustentabilidade, administração, estratégia competitiva e vantagem competitiva. Também foi realizada uma consulta em dissertações, teses e livros nas áreas apontadas anteriormente.

\section{SUSTENTABILIDADE}

Após o fim da segunda guerra mundial, para Hobsbawm (1995) entre 1948 até 1972 o mundo passou por um rápido e sustentado crescimento econômico, chamado por esse autor como "a era de ouro do século XX". Porém, no inicio dos anos setenta, a sociedade internacional começou a observar a degradação ambiental e social decorrente do presente modelo de produção, o capitalismo, sobretudo em períodos de maior crescimento econômico.

$\mathrm{Na}$ tentativa de reverter essa situação de maneira que o desenvolvimento econômico e tecnológico não fosse sinônimo de degradação ambiental e social, foi realizada na cidade de Estocolmo, na Suécia, em 1972, a Conferencia das Nações Unidas Sobre o Meio Ambiente Humano, que marcou uma etapa importante na política 
econômica mundial. Esta foi a primeira grande reunião organizada para concentrarem-se as questões ambientais e a primeira atitude mundial para tentar preservar o meio ambiente, visto que a ação antrópica gera séria degradação ambiental. Para Lago (2006) os princípios e conceitos de Estocolmo, em 1972, tornaram-se base para a evolução na área do meio ambiente. Desta resultaram inúmeras questões que continuam a influenciar e a motivar as relações entre os atores internacionais. Nessa Conferência foram aprovados 25 princípios fundamentais que orientam as ações internacionais na área ambiental, tais como: a valorização do homem dentro do ambiente como ser que o transforma, mas que depende dele para sobreviver. Além disso, promove o progresso social, cria riquezas e desenvolve a ciência e a tecnologia. (IBAMA, 2009).

Vinte anos depois da Conferência de Estocolmo, foi realizado no Rio de Janeiro a Conferencia das Nações Unidas para o Ambiente e Desenvolvimento. Na Rio 92 foi introduzido o conceito de desenvolvimento sustentável, que engloba preservação ambiental, crescimento econômico e inclusão social. Dentre os acordos internacionais fechados na conferencia podemos citar: a Convenção da Biodiversidade, a Declaração do Rio, a Convenção do Clima e também a Agenda 21.

Em 1987, as Nações Unidas, através da Comissão de Meio Ambiente e Desenvolvimento da ONU - liderada pela primeira-ministra da Noruega - Gro Harlem Brundtland, publicou o documento denominado Our Common Future, também conhecido como "Relatório Bruntland". Segundo este relatório, uma série de medidas devem ser tomadas pelos países para promover o desenvolvimento sustentável, quais sejam: garantia de acesso à água, alimentos, energia; preservação da biodiversidade e ecossistemas; desenvolvimento de tecnologias de energia limpa, aumento da produção industrial nos países não-industrializados com base em tecnologias ecologicamente adaptadas; crescimento urbano ordenado; atendimento das necessidades como saúde, escola e moradia para toda população.

Tanto as Conferencias de Estocolmo em 1972, a Rio 92 e o Relatório Bruntland serviram para a discussão e a conceitualização do desenvolvimento sustentável. Sustentabilidade é um termo usado para definir ações e atividades humanas que visam a suprir as necessidades atuais dos seres humanos, sem comprometer o futuro das próximas gerações. Ou seja, sustentabilidade está diretamente relacionada ao 
desenvolvimento econômico, promoção social e paralelamente a isto, preservando o meio ambiente.

\section{FIGURA 1: AS TRÊS DIMENSÕES DO DESENVOLVIMENTO SUSTENTÁVEL}

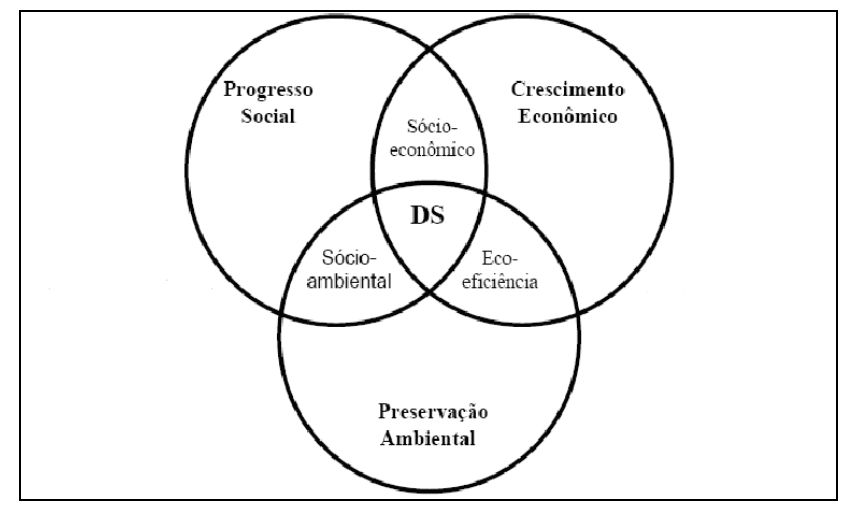

Fonte: Kraemer (2003, apud Araujo, 2006, p. 83).

\section{SUSTENTABILIDADE EMPRESARIAL E A IMPORTÂNCIA DE SEUS INDICADORES PARA IMPLEMENTAÇÃO E CONSOLIDAÇÃO DE VANTAGEM COMPETITIVA.}

A exigência de organizações empresariais mais competitivas é uma realidade cada vez maior com o aprofundamento da globalização e com a revolução nos meios de transporte e comunicação. Ante esse cenário fez-se necessário que as empresas buscassem se adaptar à concorrência global, buscando o desenvolvimento de modo a garantir sua sobrevivência e liderança no mercado.

Embora as exigências decorrentes da ampliação da competição entre as empresas ao redor do mundo sejam significativas, as mesmas tem responsabilidade na preservação do meio ambiente, bem como na promoção da qualidade de vida da sociedade.

Sendo assim, para Diekmann e Henzel (2010) a presente situação sugere uma visão mais competitiva e, sobretudo, responsável em relação à problemática sócioambiental. Uma empresa sustentável precisa ter uma postura ética, e de colaboração com a sociedade e ao meio ambiente.

Para Coral (2002) além dos fatores econômicos e estruturais, outros começam a fazer parte da responsabilidade das empresas, que são as questões do meio ambiente 
natural e as questões sociais. Para que as organizações possam contribuir para a sustentabilidade devem modificar seus processos produtivos, quando for necessário, para se tornarem ecologicamente sustentáveis. Isto implica em construir sistemas de produção que não causem impactos negativos e que estejam contribuindo para a recuperação de áreas degradadas ou oferecendo produtos e serviços que contribuam para a melhoria da performance ambiental dos consumidores e clientes de uma indústria.

Para edificação de processos sustentáveis na gestão empresarial que possam servir de base para edificação e consolidação da sustentabilidade como vantagem competitiva a criação de indicadores de desenvolvimento sustentável se faz necessária, para identificar o grau de importância de cada uma das sub dimensões da sustentabilidade, de acordo com Azevedo (2006) é importante que as empresas divulguem seus dados em relação a suas ações afinadas com os princípios da sustentabilidade, sob a forma de indicadores que sejam passíveis de comparação. No entanto, não basta apenas haver uma padronização entre as empresas; os indicadores usados devem ser apropriados, para que se possa avaliar da melhor forma possível as práticas empresariais segundo os preceitos do desenvolvimento sustentável.

O quadro abaixo sintetiza as principais sub dimensões dos indicadores econômicos, sociais e ambientais da sustentabilidade.

\section{TABELA 1: PRINCIPAIS INDICADORES PARA MENSURAÇÃO DA SUSTENTABILIDADE EMPRESARIAL}

\begin{tabular}{|l|l|l|}
\hline \multicolumn{1}{|c|}{$\begin{array}{l}\text { Indicadores } \\
\text { Econômicos }\end{array}$} & Indicadores Ambientais & Indicadores Sociais \\
\hline - Produção; & - Consumo de energia; & • Indicadores \\
- Volume total de & - Emissões de gases; & funcionais; \\
\hline vendas; & - Consumo de materiais & • Admissões no \\
\hline - Exportação; & reciclados; & período; \\
\hline - Faturamento; & - Substituição de & - Mulheres \\
- Folha de pagamento; & materiais; & empregadas; \\
\hline - Tributos. & - Consumo de recursos & - Índice de \\
\hline
\end{tabular}




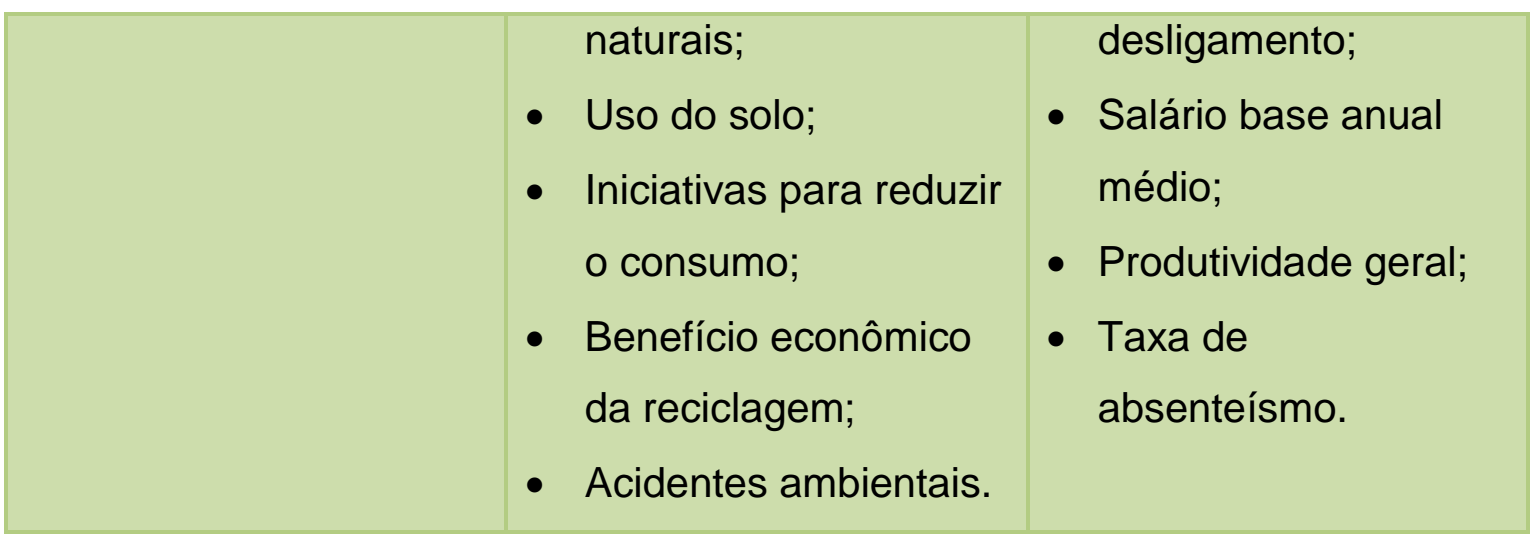

Fonte: Elaborado pelos autores

Através da análise dos indicadores de sustentabilidade, as empresas podem "medir" seu nível de sustentabilidade, possibilitando assim desenvolver as melhores práticas na busca do desenvolvimento sustentável e conseqüentemente criar valor a todos os seus stakeholders: colaboradores, fornecedores, acionistas, sociedade, comunidade, governo e, sobretudo, os clientes.

Esta agregação de valor vai ao encontro da definição de vantagem competitiva, que de acordo com Porter (1985, p.3) fundamentando, portanto a importância da prática da sustentabilidade para edificação e consolidação de vantagem competitiva para as organizações empresariais.

\begin{abstract}
"Vantagem competitiva surge, fundamentalmente, do valor que uma empresa é capaz de criar para seus compradores, valor este que excede o custo da empresa em criá-lo. Valor é o que os compradores estão dispostos a pagar, e valor superior provém da oferta de preços inferiores aos dos concorrentes para benefícios equivalentes ou o fornecimento de benefícios únicos que mais do que compensam um preço superior."
\end{abstract}

Como fundamentação ao ante exposto de acordo com BMFBOVESPA (2011) as empresa listadas nos Índice de Índice de Sustentabilidade Empresarial negociado na Bolsa em 2010 tiveram valorização de 5,84\%, maior do que o Índice lbovespa, de 1,04\%.

\title{
4. CONCLUSÃO
}


Ante o cenário de complexidade no inicio do século XXI, com a ampliação da concorrência em escala mundial e a degradação ambiental com fatos como: aumento do nível dos oceanos, aumento de doenças transmissíveis por mosquitos e outros vetores, mudança na dinâmica pluvial, intensificação de fenômenos climáticos extremos, ampliação do processo de desertificação, perda de regiões agricultáveis, falta de água, aumento de fluxos migratórios, escassez de alimento, inflação, queda na renda da população, aumento do desemprego, aumento das desigualdades sociais, aumento do número de conflitos e da violência em geral é de importância superlativa que as empresas possam se adaptar à concorrência globalizada e liderar as transformações ambientais e sociais que se fazem necessárias.

Nesse sentido a sustentabilidade é um termo usado para definir ações e atividades humanas que visam suprir as necessidades atuais dos seres humanos, sem comprometer o futuro das próximas gerações, relacionadas ao desenvolvimento econômico, promoção social e paralelamente a isto preservando o meio ambiente - conceito este que foi edificado na Conferencia das Nações Unidas Sobre o Meio Ambiente Humano em 1972 em Estocolmo, em 1992 na Conferencia das Nações Unidas para o Ambiente e Desenvolvimento e também através do Relatório Bruntland, publicado em 1987. Este conceito responde positivamente à pergunta orientadora desse artigo - a aplicação dos princípios sustentáveis através dos indicadores econômicos (produção, volume total de vendas, exportação, faturamento, folha de pagamento e tributos) ambientais (consumo de energia, emissões de gases, consumo de materiais reciclados; substituição de materiais, consumo de recursos naturais, uso do solo, iniciativas para reduzir o consumo, benefício econômico da reciclagem e acidentes ambientais) e sociais (indicadores funcionais, admissões no período, mulheres empregadas, índice de desligamento, salário base anual médio, produtividade geral e taxa de absenteísmo) pode edificar e consolidar vantagem competitiva pois estes princípios agregam valor a todos os stakeholders da empresa.

Essa situação pode ser constatada através do índice de Sustentabilidade Empresarial negociado na Bolsa de Valores de São Paulo, em 2010. As empresas listadas nesse índice obtiveram uma superação em $5,84 \%$ maior em comparação com as empresas que listam o Índice Ibovespa, que ficou em 1,04\%. 
Portanto, as empresa que quiserem se tornar e se manter competitivas no mercado globalizado gerando valor econômico, promovendo o desenvolvimento social e a preservação ambiental, devem aplicar os princípios sustentáveis, norteados pelos indicadores de sustentabilidade na gestão empresarial.

\section{REFERÊNCIAS}

AZEVEDO, Ana Luiza Vieira. Indicadores de sustentabilidade empresarial no Brasil: uma avaliação do Relatório do CEBDS; Disponível em:

<http://www.redibec.org/IVO/rev5_06.pdf> Acesso em: 10 jun. 2013.

BMFBOVESTA. Indicadores de sustentabilidade empresarial. Disponível em< http://www.bmfbovespa.com.br/Indices/download/ISE_2011_WS-processo-seletivo.pdf>. Acesso em: 10 jun. 2013.

CORAL, Elisa. Modelo de planejamento estratégico para a sustentabilidade empresarial. 2002. 282f. Tese (Doutorado em Engenharia da Produção). Universidade Federal de Santa Catarina, Florianópolis - SC, 2002.

HOBSBAWN, Eric. A era dos extremos: o breve século XX. 1941-1991. São Paulo: Companhia das Letras, 1995. p. 90.

Instituto Brasileiro do Meio Ambiente e dos Recursos Naturais Renováveis. História. Disponível em<http://www.ibama.gov.br/am/institucional/historia.htm>. Acesso em: 10 jun. 2013.

KRAEMER, Maria Elizabeth Pereira. Contabilidade rumo á pós-modernidade: um futuro sustentável, responsável e transparente, 2005. In ARAUJO, Geraldino. O Processo de implantação da sustentabilidade em frigoríficos: Estudo de caso no Frigorífico Independência. 2006. 169 f. Dissertação (Mestrado em Agronegócio) Universidade Federal do Mato Grosso do Sul, Campo Grande, 2006.

LAGO, André Aranha Correia. Estocolmo, Rio, Johanesburgo: O Brasil e as três conferências ambientais das Nações Unidas. Brasília: Fundação Alexandre de Gusmão, 2006. $276 \mathrm{p}$.

Porter, Michael. Competitive advantage: creating and sustaining superior performance. New York: Free Press, Collier Macmillan. 1985 